\title{
Female house crickets, Acheta domesticus, prefer the chirps of large males
}

\author{
DAVID A. GRAY \\ Department of Biology, The U niversity of $\mathrm{N}$ ew M exico, A lbuquerque, NM 87131, U.S.A. \\ ( Received 15 J uly 1996; initial acceptance 140 ctober 1996; \\ final acceptance 27 February 1997; M S. number: $A 7655 R$ )
}

\begin{abstract}
A bstract. This study demonstrates that invertebrate acoustic signals can provide information about male phenotypic attributes, and that females can use this acoustic information in mate choice to select a phenotypically superior mate. I investigated the relationships between a male acoustic sexual signal, the phenotype of the signaller, and the female response to signal variation. I recorded and analysed the calling songs of male house crickets, Acheta domesticus. The analyses showed that chirps convey information about male size. With the exception of amplitude, the mean number of pulses per chirp was the best predictor of male size. I performed a laboratory tape-playback experiment to determine female preference during phonotaxis. F emales preferred tapes playing the chirps of large males, specifically chirps with a greater number of pulses per chirp. Selection on the female preference is discussed.
\end{abstract}

(C) 1997 The Association for the Study of A nimal Behaviour

Sexual selection has become a widely studied and well documented phenomenon (A ndersson 1994). A ccording to current theory, sexual signals should be expensive and reveal male quality. A coustically signalling species have been the target of many studies of sexual communication (Bailey 1991; Andersson 1994). In such species, however, the signal and the phenotype of the signaller may be decoupled more easily than in species that signal by displaying their phenotype directly. Several studies of acoustic-signalling systems have found a relationship between male phenotypic attributes and features of the acoustic signal, while other studies have not (Searcy \& Andersson 1986; A ndersson 1994).

Sexual selection is often viewed as consisting of several operational components, such as malemale competition, female choice and sperm competition (M øller 1994). M any of these components can be separated in field crickets (Orthoptera: $\mathrm{G}$ ryllidae). $M$ ale field crickets produce three types of acoustic signals: aggressive chirps, which are used in male-male fights; calling song, used to attract females; and courtship song, used directly prior to mating once a female has located a male (A lexander 1961). The mating system of most field crickets is simple: males compete for calling

Correspondence: D. Gray, Biological Sciences, Brock U niversity, St Catharines, Ontario L $253 \mathrm{~A} 1$, Canada (e-mail: dgray@spartan.ac.brocku.ca). burrows or shelters, males call to attract females (calling song), and females locate males by phonotaxis (A lexander 1961; Huber \& Thorson 1985). $\mathrm{N}$ on-calling males may cluster around a calling male and attempt to intercept responding females, particularly at high densities (Cade 1980, 1981; Cade \& Cade 1992). When females locate males, there is typically a period of mutual antennation, courtship song, and finally mating. $M$ ating consists of the female mounting the male's back and the transfer of a spermatophore (A lexander 1961; Alexander \& Otte 1967; Boake 1983). Although mate-guarding behaviour occurs (K halifa 1950; D. A. Gray, personal observation of Acheta domesticus), females often mate multiply (Sakaluk \& Cade 1983; Solymar \& Cade 1990). Female choice among males occurs during phonotaxis to calling males (Hedrick 1986; Simmons 1988; Wagner et al. 1995), although mate choice is not necessarily restricted to phonotaxis.

This study was undertaken to determine whether the chirps of male house crickets, A. domesticus, provide females with information about male morphological attributes, and whether females use that information during mate selection. Because of the acoustic communication system, this study has the potential to provide information regarding two inter-related issues in sexual selection: functionality of the female preference and sexual signal design. 


\section{METHODS}

\section{C rickets}

The crickets were from a laboratory stock population obtained from Bassett's $C$ ricket $R$ anch (Visalia, California, U.S.A .) via a local pet supply store. I added additional crickets periodically to ensure genetic diversity. I reared the crickets in 3.79-litre (1 gallon) glass jars with a sand substrate, an egg carton perch and ad libitum food (cat chow). I provided water by adding it directly to the sand. R earing jars were checked daily for newly emerged adults. $\mathrm{N}$ ew adults were removed from the jars, transferred to individual numbered containers ( $6.5 \mathrm{~cm}$ height, $3.5 \mathrm{~cm}$ diameter), coldanaesthetized, weighed and measured. I took the following measurements on a large sample of males and females: pronotum length and width, left and right hind tibia length, and left and right forewing length (in males the forewings are modified for calling). I made measurements under a dissecting microscope $(\times 4)$ with dial callipers accurate to the nearest $0.05 \mathrm{~mm}$. I returned the crickets to their individual containers and provided food ad libitum and daily water (two drops from an eye dropper onto the food). Both sexes were physically (but not acoustically) isolated from other individuals, and so were virgin.

\section{Recording and A nalysis of C alling Song}

Subjects were males aged a minimum of 10 days post-adult moult $(\bar{X} \pm \mathrm{SD}=14.4 \pm 3.6$, range $=10$ 23 days). When a male was calling from within its individual container, I gently placed the container, with the lid removed, into a sound-insulated recording chamber. L ocation within the chamber was identical for all crickets (no crickets escaped their individual containers despite the removal of the lids). I placed the crickets $25 \mathrm{~cm}$ from the microphone. When calling resumed, I recorded the crickets onto TDK SA 90 IEC II super avilyn tapes using a portable recorder (Sony WM -D 3 Professional Walkman). Crickets can be tentative when they first resume calling. To sample a portion that represents the maximum chirping output, I recorded several minutes for each individual. Tapes were reviewed by ear to identify a 'best' section, that is, a period of consistent clear chirping that had the maximum auditory stimulus (based mainly on loudness and chirp rate) for each cricket. I performed the review blind to the morphological measurements. I transferred 16 consecutive chirps from this 'best' section to a computer for analysis. Transfer was through a Sony STR-D 315 tuner/amplifier directly to a sound analysis program (Canary 1.1, Cornell Laboratory of Ornithology, Ithaca, N ew Y ork). All recording, amplifying and input levels were identical for all crickets.

I analysed waveform and spectrogram representations ( $F$ ig. 1). I counted the number of pulses per chirp and measured the peak amplitude, the frequency of the peak amplitude and the length of the inter-chirp interval. I analysed the first 15 chirps for the number of pulses per chirp, the peak amplitude and the frequency of the peak amplitude; I input the sixteenth chirp to allow 15 inter-chirp intervals to be measured. The 15 measurements per cricket were then averaged for each chirp parameter.

\section{Female Choice Trials}

I chose 10 of the computerized calls for female choice trials. These calls were chosen to represent close to the maximum range of calling parameters observed. I recorded 10 30-s endless loop tapes from the computer, again via the tuner/amplifier. The choice arena was a PVC plastic trough $76.2 \mathrm{~cm}$ long, $7.6 \mathrm{~cm}$ wide at the base, and $10.8 \mathrm{~cm}$ wide at the top. I placed one speaker (Sony SR S-A 30) at each end of the trough. I played the endless loop tapes through the speakers from the portable recorders. To ensure that the smooth plastic surfaces of the trough did not create echoes or otherwise distort the male calling song, I re-recorded chirps played into the trough, and then compared them with the original and with a separate re-recording made across a foam pad surface with no side walls. Two sets of re-recordings were made. One set consisted of male chirps re-recorded in the trough at the midpoint ( $38 \mathrm{~cm}$ from the speaker), the second set consisted of chirps re-recorded $19 \mathrm{~cm}$ from the speaker; equivalent distances were used for the re-recordings made across the foam pad. No echoes or other acoustic distortions were observable (Figs 2 and 3 ), although the levels of white noise were slightly higher in all re-recordings than in the original.

I tested females under dim lighting conditions (4.8 Ix, Gossen Luna-Pro light meter). Between 

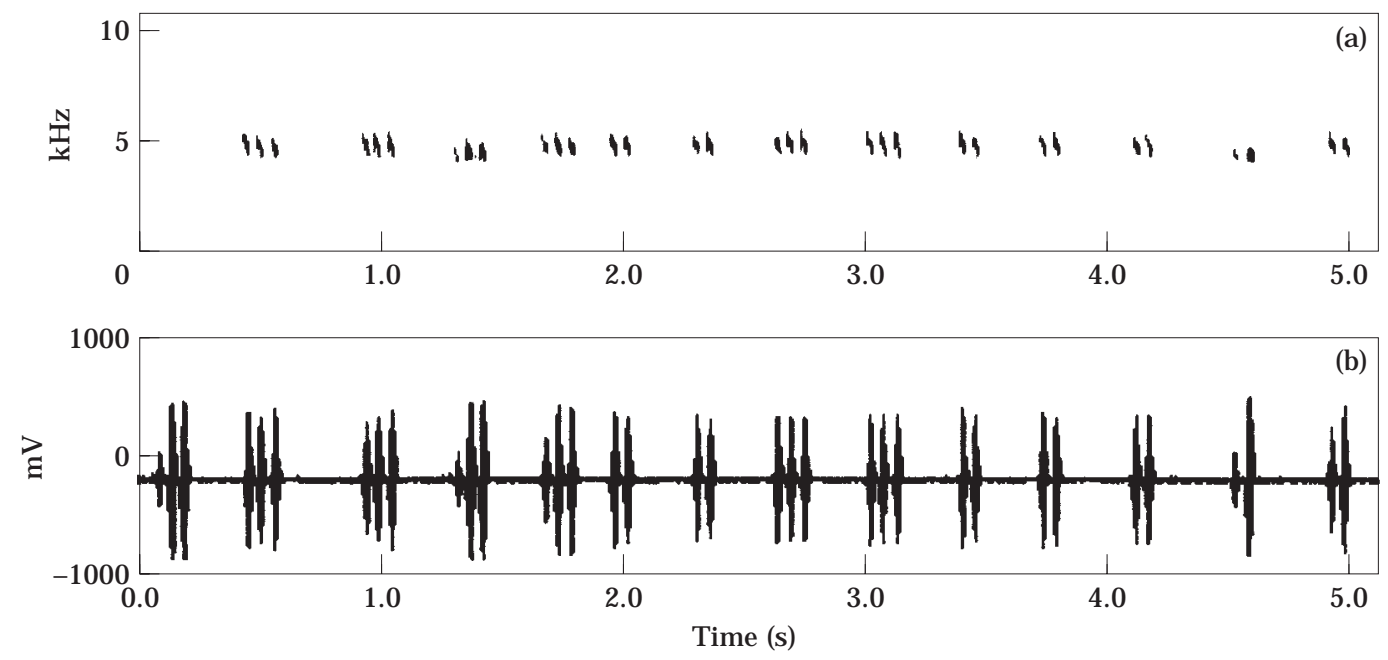

Figure 1. (a) Spectrogram representation of a series of chirps. (b) Waveform representation of the same series of chirps. The inter-chirp interval is the time from the end of one chirp to the start of the next.
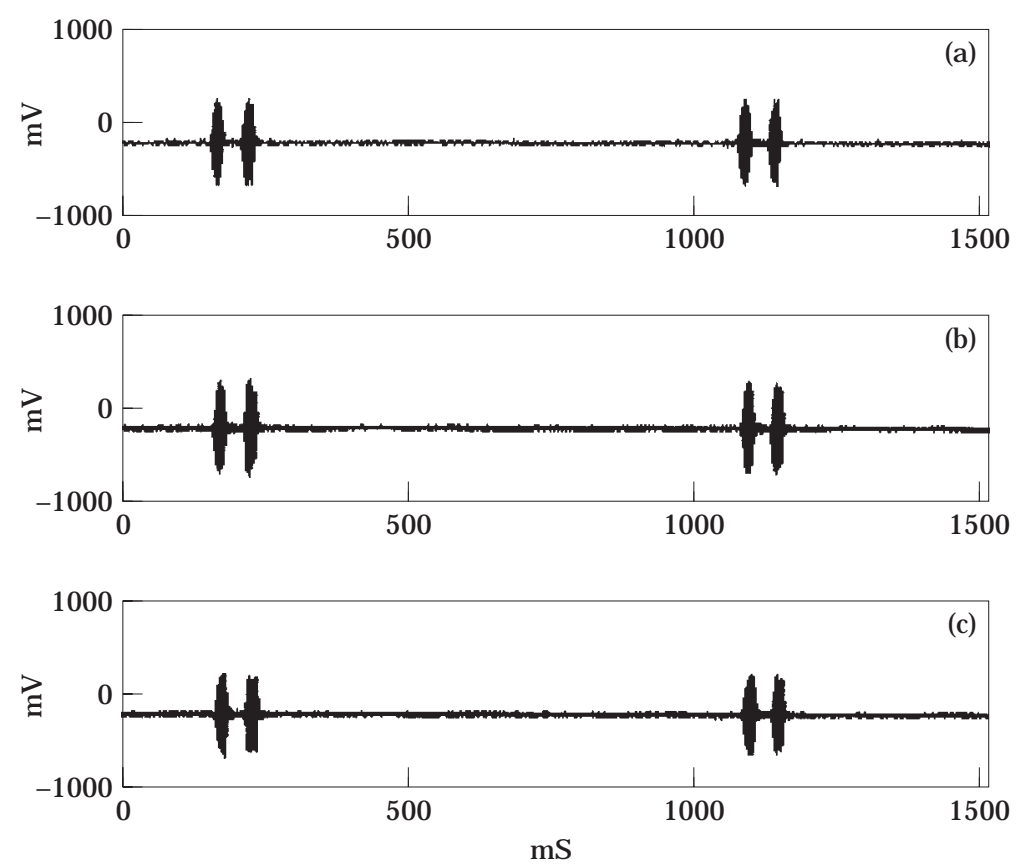

Figure 2. Waveforms of a series of chirps played back and re-recorded to ensure that the choice apparatus did not distort the signal. (a) Original stimulus tape; (b) rerecording of (a) made $38 \mathrm{~cm}$ from the speaker in the plastic trough; (c) re-recording of (a) made $38 \mathrm{~cm}$ from the speaker over a foam pad substrate.

trials, the speakers and the trough were wiped with a wet sponge to eliminate odour cues left by previous females. A R adio Shack 33-2050 sound level meter was used to set sound pressure level
(SPL) to an apparent $80 \mathrm{~dB}$ at the midpoint of the trough. Due to the mass of the needle and the short duration of the cricket chirps, however, this meter systematically underestimated the SPL 

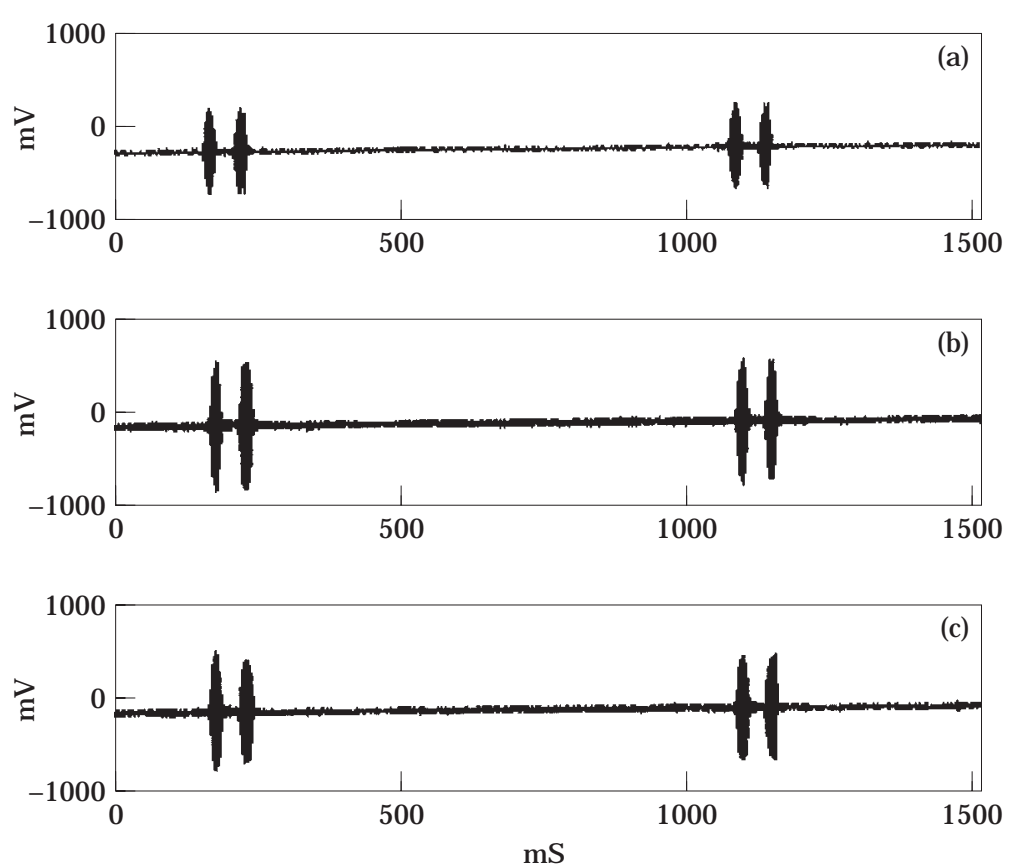

Figure 3. Waveforms of a series of chirps played back and re-recorded to ensure that the choice apparatus did not distort the signal. (a) Original stimulus tape; (b) re-recording of (a) made $19 \mathrm{~cm}$ from the speaker in the plastic trough; (c) re-recording of (a) made $19 \mathrm{~cm}$ from the speaker over a foam pad substrate.

of chirps. The SPL used was actually $87 \mathrm{~dB}$ (measured after the experiments were complete with a Radio Shack 33-2055 digital sound level meter). A n upturned egg-carton cup was placed at the midpoint of the trough for shelter. A virgin female aged 10 days post-adult moult was gently coaxed into the egg-carton shelter. I then covered the female and the shelter with an upturned modified yoghurt cup $(7.6 \mathrm{~cm}$ tall, $7.3 \mathrm{~cm}$ diameter at base, i.e. the original top). A 3-min acclimation period was allowed, with the tapes playing, for most females. For females that appeared disturbed by the transfer to the shelter, I allowed 5 min for acclimation. After the acclimation period, the yoghurt cup was slowly lifted by hand, and the female's behaviour was timed and observed. The first speaker physically touched (including antennated) by the female was scored as her choice. If a female made no choice within 3 min, I discontinued the trial. Ten pairs of tapes were tested with five females per tape-pair. To eliminate side bias, I switched which side presented the tape of the larger male after every two trials. I used each tape in one to three pairs, that is, tape-pairs were unique, but some of the individual tapes comprising half of a pair were used more than once.

\section{RESU L T S}

\section{$M$ ale $M$ orphology and $C$ hirp $C$ haracteristics}

Weight at the adult moult proved to be the best measure of body size. Table I shows the correlations between mass and several other possible measures of body size for a large sample of both males and females (all measures were logtransformed prior to analysis; sample sizes vary slightly due to individuals with missing or broken body parts). All correlations of univariate measures exceeded 0.84 for males and 0.79 for females. A multivariate measure of body size was also created. Principal components analysis combined mass, pronotum length and width, hind tibia length and wing length. The first principal component retained 88 and $84 \%$ of the original variation for males and females, respectively. F or 
T able I. Correlations between weight at the adult moult (as a measure of body size) and several other morphological variables

\begin{tabular}{llrcc}
\hline \multicolumn{1}{c}{ Variable } & \multicolumn{1}{c}{ Sex } & N & $r$ & $P$ \\
\hline \multirow{3}{*}{ Pronotum length } & M ale & 124 & 0.835 & 0.0001 \\
& F emale & 103 & 0.844 & 0.0001 \\
Pronotum width & M ale & 124 & 0.884 & 0.0001 \\
& F emale & 103 & 0.840 & 0.0001 \\
Hind tibia length & M ale & 118 & 0.871 & 0.0001 \\
Wing length & Female & 93 & 0.792 & 0.0001 \\
& M ale & 117 & 0.851 & 0.0001 \\
PCA 1* & F emale & 93 & 0.809 & 0.0001 \\
& M ale & 116 & 0.961 & 0.0001 \\
& F emale & 88 & 0.950 & 0.0001 \\
\hline
\end{tabular}

*PCA $1=$ The first principal component from a principal components analysis. W eight, pronotum length, pronotum width, hind tibia length and wing length loadings were, respectively: $0.459,0.443,0.457,0.445,0.433$ for males, and $0.464,0.455,0.447,0.432$, 0.437 for females. PCA 1 explains 88 and $84 \%$ of the original variation for males and females, respectively.

both males and females, mass loaded slightly heavier than the other univariate measures, and so showed the strongest correlation with the first principal component $(r=0.96$ and 0.95 for males and females, respectively). I therefore used weight at adult moult as a measure of body size throughout.

$M$ ale weight, age and chirp characters were log-transformed prior to analysis. Larger males were louder $(r=0.564, N=46, P<0.0001)$ and had more pulses per chirp $(r=0.444, N=46, P=0.002)$ than smaller males ( $F$ igs 4 and 5 ). Size appeared unrelated to frequency and only weakly related to the inter-chirp interval (frequency: $r=0.010$, $N=46, P>0.05$; inter-chirp interval: $r=-0.227$, $N=46,0.10>P>0.05$ ). $M$ ale age did not correlate with any of the chirp characters examined $(N=46$, amplitude: $r=0.06, P=0.69$; pulses per chirp: $r=-0.12, P=0.44$; frequency: $r=-0.06, P=0.68$; inter-chirp interval: $r=-0.06, P=0.69$ ), nor with the residuals from regressions relating amplitude and pulses per chirp to male weight (male age and residual amplitude: $r=0.08, N=46, P=0.56$; male age and residual pulses per chirp: $r=-0.12$, $N=46, P=0.42$ ).

\section{F emale P reference}

M ost females responded quickly to the tapes. The mean $\pm \mathrm{SD}$ trial time of females that responded $(\mathrm{N}=50)$ was $52.8 \pm 43.6 \mathrm{~s}$. Only two

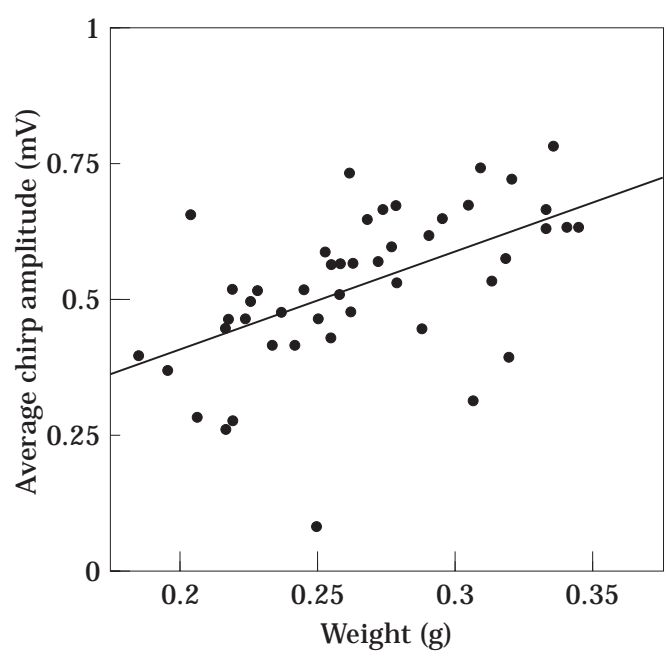

Figure 4. The relationship between male weight and the average peak amplitude of chirps. Points are means of 15 chirps.

females that received the 3-min acclimation did not respond within the allotted time ( $3 \mathrm{~min}$ ). Both of these females were re-tested successfully later the same day (such that they were still 10 days old). Of the females that received a 5-min acclimation prior to the trial $(\mathrm{N}=6)$, two did not respond within the $3 \mathrm{~min}$. One of these was successfully re-tested the next day (at age 11 days); the other was discarded because she lost her right foreleg prior to re-testing. 


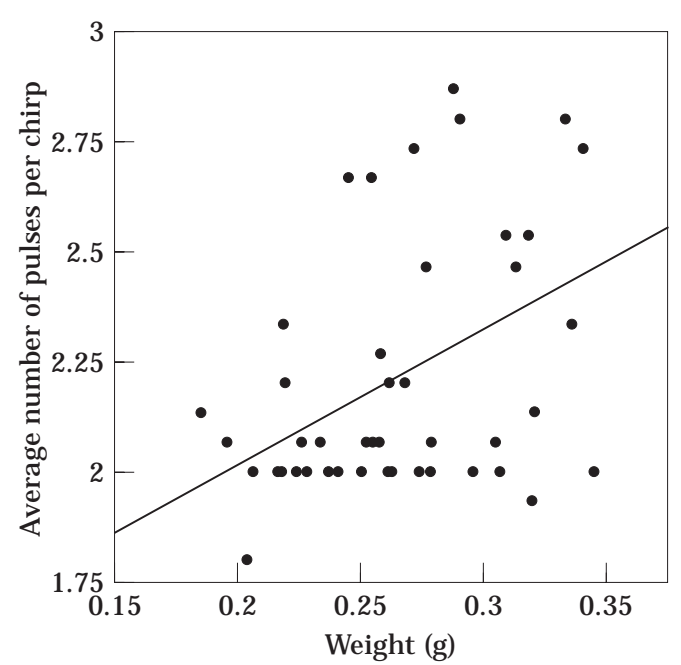

Figure 5. The relationship between male weight and the average number of pulses per chirp. Points are means of 15 chirps.

For each pair of stimulus tapes, five females were tested. This can lead to pseudo-replication of data. Therefore, the data were analysed two ways: treating females as independent sample units, and treating pairs of tapes as independent sample units. Treating females as independent sample units, 37 of 50 females chose the speaker playing the tape of the larger male (log likelihood ratio test with continuity correction: $\mathrm{G}_{\mathrm{adj}, 1}=10.99, \quad \mathrm{P}<0.001$ ). Treating tape-pairs as independent sample units, in 9 of 10 tape-pairs, the tape playing the call of the larger male was chosen in the majority of the trials, that is, three or more of the five trials (log likelihood ratio test with continuity correction: $G_{a d j, 1}=5.41$, $P<0.02)$.

Forty-two of the 50 females were available for re-testing 3 days later. $F$ emales were re-tested with the same two stimulus tapes, played from the same ends of the choice apparatus, as on the first trial. Treating females as independent sample units, 28 of 42 chose the tape of the larger male (log likelihood ratio test with continuity correction: $\left.G_{a d j, 1}=4.09, P<0.05\right)$. Treating tape-pairs as independent sample units did not give a significant result (in six of nine tapepairs, the tape of the larger male was chosen more frequently; in one tape-pair each tape was chosen twice).

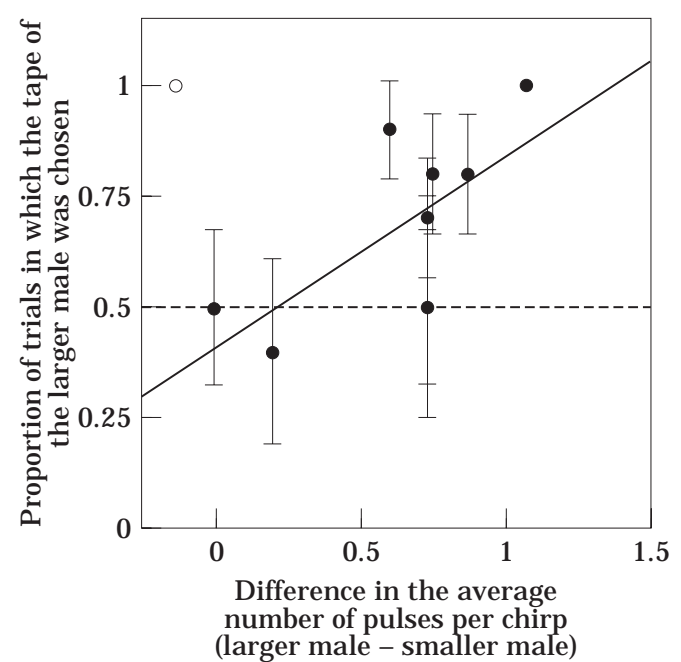

Figure 6. The probability that a female chose the tape of the larger male depended on the difference between the tapes in the number of pulses per chirp. $\bigcirc$ : outlying tape-pair (see text).

Only 25 of the 42 re-tested females made the same choice they had previously. The probability that a female would change her choice seemed to depend on her initial choice, however: $32 \%$ (10 of 31) of females that chose the tape of the larger male on the first trial switched their choice on the second trial, and $64 \%$ (seven of 11 ) of females that chose the tape of the smaller male on the first trial switched their choice on the second trial ( $F$ isher's exact test: $P=0.086$, two-tailed).

\section{C hirp C haracteristics and F emale P reference}

I tested which of the chirp characters was the best predictor of female choice by pooling the data from the first and second trials. U sing all of the data means that, within a tape-pair, a female could have chosen the tape of the larger male 0 of 1,0 of 2, 1 of 1,1 of 2, or 2 of 2 times. I used logistic regression to test whether the probability that a female chose the tape of the larger male depended on the difference in chirp characters between the two tapes in the pair. Figure 6 shows the relationship between the proportion of trials in which females chose the tape of the larger male and the difference in the number of pulses per chirp between the two males. A nalysing all of the data did not give a significant result (maximum 
Table II. Summary of studies of sexual selection by female choice in field crickets

\begin{tabular}{|c|c|c|c|c|}
\hline \multirow[b]{2}{*}{ Gryllus species } & \multicolumn{3}{|c|}{ F emale preferences* } & \multirow[b]{2}{*}{ R eference } \\
\hline & A coustic & M orphological & Other & \\
\hline \multirow[t]{2}{*}{ bimaculatus } & $\begin{array}{l}\text { Louder, faster, chirps; } \\
\text { more pulses per chirp }\end{array}$ & Size & & Simmons (1988) \\
\hline & & N ot size & $\begin{array}{l}\text { A ge, fewer } \\
\text { parasites }\end{array}$ & Simmons \& Zuk (1992) \\
\hline campestris & $\begin{array}{l}\text { Pure tones, } \\
\text { low carrier frequency }\end{array}$ & Size, symmetry & Age & $\begin{array}{l}\text { Simmons (1995); } \\
\text { Simmons \& R itchie (1996) }\end{array}$ \\
\hline veletis & & N ot size & $\begin{array}{l}\text { A ge, fewer } \\
\text { parasites }\end{array}$ & Zuk $(1987,1988)$ \\
\hline pennsylvanicus & & N ot size & $\begin{array}{l}\text { A ge, fewer } \\
\text { parasites }\end{array}$ & Zuk $(1987,1988)$ \\
\hline integer [T exas]† & M ore pulses per trill & $\begin{array}{l}\text { Pulses per trill } \\
\text { unrelated to size } \\
\text { No net } \\
\text { selection on size }\end{array}$ & $\begin{array}{l}\text { Pulses per trill } \\
\text { unrelated to age }\end{array}$ & $\begin{array}{l}\text { Souroukis et al. (1992); } \\
\text { Wagner et al. (1995) } \\
\text { Cade \& Cade (1992) }\end{array}$ \\
\hline integer [California]† & Long calling bout duration & & & Hedrick (1986) \\
\hline
\end{tabular}

*Indicates experimentally demonstrated preferences, and/or traits correlated with preferred characters or pairing success.

†California and Texas populations of G. integer are probably separate species (W eissman et al. 1980).

likelihood estimate $=0.60, \mathrm{~W}$ ald $\chi_{1}^{2}=1.02, \mathrm{~N}=50$ females, 92 trials, $P=0.31$ ). There appears to be a strong statistical outlier, however (Fig. 6). A nalysing the data without the outlying tape-pair gave a strong and significant result: the bigger the difference in the number of pulses per chirp between the two tapes, the greater the probability that females chose the tape of the larger male (maximum likelihood estimate $=2.13, W$ ald $\chi_{1}^{2}=8.39, \quad N=45$ females, 82 trials, $P=0.004$ ). Although this was a post hoc analysis, there may be biological as well as statistical reasons to consider the outlying tape-pair separately. The difference in the average number of pulses per chirp between the two crickets in this pair was very small $(-0.13)$. As chirp amplitude was equalized, females comparing these two tapes lacked size information based on amplitude and pulses per chirp. F emales may then have relied on differences in inter-chirp interval, which was weakly related to size $(r=-0.227, N=46, P<0.1$, see above). The difference in inter-chirp interval was large (1.27 versus $4.14 \mathrm{~s}$, larger and smaller, respectively). This interpretation is bolstered by an analysis of the effect of differences in interchirp interval on the probability that females chose the tape of the larger male (W ald $\chi_{1}^{2}=3.38$, $P=0.066)$. The difference in frequency was not a useful predictor (W ald $\chi_{1}^{2}=1.96, \mathrm{P}>0.05$ ).

\section{DISCUSSION}

This study demonstrated a relationship between male morphology and characteristics of an acoustic signal used to attract females. Studies such as this have been conducted successfully in several vertebrates, notably amphibians (A ndersson 1994), but have been relatively rare in invertebrates. Although numerous studies have established preferred acoustic characters (A ndersson 1994), few have related the production of these characters to male phenotypic attributes. The number of syllables per phrase was reliably related to male size, and females preferred more syllables per phrase in Scudderia curvicauda, an acousticsignalling katydid (Tuckerman et al. 1993) and in the cricket Gryllus bimaculatus (Simmons 1988). Simmons \& Ritchie (1996) showed that female $G$. campestris preferred pure tones with low carrier frequency produced by large symmetrical calling wings. Together, these studies suggest that invertebrate acoustic cues may provide females with honest indicators of male phenotypic condition.

Although field crickets have been extensively studied over the last several decades, few studies have demonstrated sexual selection on male size (Table II). Other researchers have investigated sexual selection on aspects of $A$. domesticus calling 
song. Crankshaw (1979) found that females showed a phonotactic preference for the calling songs of dominant males. Crankshaw reported that the calls of subordinate males had higher chirp rates and that dominant males had a 'brighter' chirp. Crankshaw gave no information about male body size, although in crickets dominance is probably related to size (A lexander 1961; Dixon \& Cade 1986; Souroukis \& Cade 1993). In a study of female phonotaxis to electronically synthesized male calling songs, calls with three pulses per chirp were preferred to calls with either two or four (Stout et al. 1983; see also Stout \& M CG hee 1988). When this natural range of variation was extended, calls with either one or five pulses per chirp were even less preferred. These results suggest that the number of pulses per chirp may be under stabilizing selection.

Stout et al.'s (1983; Stout \& M CG hee 1988) results may be reconciled with mine as follows. Within the typical range of variation (2-3 pulses per chirp), directional selection favours larger individuals with more than the median number of pulses per chirp, but the female preference is specific to this range of variation. In principle, species recognition problems could restrict the preference, such that it is bounded within a certain range of variation. This possibility is speculative, however. A nother difference between this study and those by Stout et al. is that we derived our crickets from separate commercial stocks. Since selection regimes of animals under culture differ from those in the wild, and separate cultures may experience varying conditions, the different results may stem from differences in the source populations.

If females prefer chirps with more pulses per chirp, then why do smaller males not add more pulses to their chirps? One possibility is that smaller males, with fewer pulses per chirp, may not be at that great a reproductive disadvantage. Smaller males may be more likely to use an alternative mating strategy, satellite behaviour, that 'parasitizes' the calling abilities of larger males. For example, smaller male G. integer [T exas] called less than larger males at high densities (Cade $\&$ Cade 1992). If mating strategy, size and calling behaviours are entwined, genetic correlations among these traits are likely; Cade (1981) demonstrated a genetic component to male mating strategy in G. integer [T exas]. A second possibility is that smaller males are energetically limited. Each pulse is the product of a single wing stroke. The total amount of energy expended is proportional to the number of wing strokes and therefore the number of pulses produced (Prestwich \& Walker 1981). In trilling species of crickets and katydids, the energetic costs of calling can be high. For example, the cost of calling was measured as 10-16 times that of resting in A nurogryllus arboreus (Prestwich \& Walker 1981), with similar results in $\mathrm{Neoconocephalus} \mathrm{robustus}$ (Stevens \& Josephson 1977). Chirping species, however, produce far fewer pulses and so will have greatly reduced energetic expenditures compared with these trilling species.

Why do females prefer larger males? Sexual selection favouring larger males is common (A ndersson 1994). K odric-Brown \& Brown (1984) discussed possible general advantages applicable to numerous taxa. Several factors are likely to be important: (1) phenotypic quality may reflect genetic quality; (2) if size is inherited, then choosy females may have more fecund daughters and more competitive and attractive sons; (3) females may receive direct benefits. All three of these possibilities have empirical support in A. domesticus: large males are more symmetrical and have greater longevity under laboratory conditions (Gray 1997; see also Simmons 1995 for G. campestris); body size is heritable in several cricket species (G. bimaculatus: Simmons 1987; G. pennsylvanicus: Simons \& Roff 1994), including A. domesticus (Gray 1997); larger male A.domesticus produce larger spermatophores (G ray 1997). Larger spermatophores may benefit females because both nutritional investment and accessory substances may increase female fecundity. In A . domesticus, spermatophore wet weight is less than $1 \%$ of male mass, so a large nutritional role is unlikely, although trace nutrients may be important. Spermatophores contain accessory substances that promote the conversion of arachidonic acid to prostaglandins within the female; female fecundity and oviposition are enhanced by the prostaglandins (Destephano \& Brady 1977; Destephano et al. 1982; M urtaugh \& Denlinger 1985, 1987). There are thus several potential benefits of the female's preference that are not mutually exclusive.

\section{ACKNOWLEDGMENTS}

My thanks to my dissertation committee, A. Kodric-Brown, J. H. Brown, J. D. Ligon and 
M. Zuk. R. Thornhill also provided advice and discussion. Two anonymous referees provided excellent critiques that greatly improved the manuscript. M y work was supported by an N SF $G$ raduate Fellowship, and by the University of $\mathrm{N}$ ew M exico SR A C, GRAC, and RPT grants.

\section{REFERENCES}

A lexander, R. D. 1961. A ggressiveness, territoriality, and sexual behavior in field crickets (Orthoptera: G ryllidae). B ehaviour, 17, 130-223.

A lexander, R. D. \& Otte, D. 1967. The evolution of genitalia and mating behavior in crickets (G ryllidae) and other Orthoptera. M isc. Publ. M us. Z ool. Univ. $\mathrm{M}$ ich., 133, 1-62.

Andersson, M. 1994. Sexual Selection. Princeton, $\mathrm{N}$ ew J ersey: Princeton U niversity Press.

Bailey, W. 1991. A coustic Behaviour of Insects: An Evolutionary Perspective. London: Chapman $\& \mathrm{H}$ all.

Boake, C. R. B. 1983. M ating systems and signals in crickets. In: Orthopteran M ating Systems: Sexual Competition in a Diverse Group of Insects ( $\mathrm{Ed}$. by D. T. G wynne \& G. K. M orris), pp. 28-44. Boulder, Colorado: Westview Press.

Cade, W. H . 1980. A Iternative male reproductive behaviors. Fla Entomol, 63, 30-45.

Cade, W. H. 1981. A Iternative male strategies: genetic differences in crickets. Science, 212, 563-564.

Cade, W. H. \& Cade, E. S. 1992. M ale mating success, calling and searching behaviour at high and low densities in the field cricket, Gryllus integer. A nim. Behav., 43, 49-56.

Crankshaw, 0. S. 1979. Female choice in relation to calling and courtship songs in Acheta domesticus. A nim. B ehav., 27, 1274-1275.

Destephano, D. B. \& Brady, U. E. 1977. Prostaglandin and prostaglandin synthetase in the cricket, Acheta domesticus. J. Insect P hysiol., 23, 905-911.

Destephano, D. B., Brady, U. E. \& F arr, C. A. 1982. Factors influencing oviposition behavior in the cricket, A cheta domesticus. Ann. entomol. Soc. Am., 75, 111-114.

Dixon, K. A. \& Cade, W. H. 1986. Some factors influencing male-male aggression in the field cricket Gryllus integer (time of day, age, weight and sexual maturity). A nim. Behav., 34, 340-346.

Gray, D. A. 1997. Sexual selection, phenotypic and genetic quality in house crickets, A cheta domesticus. Ph.D. thesis, The $U$ niversity of $\mathrm{N}$ ew $\mathrm{M}$ exico.

H edrick, A . V. 1986. F emale preferences for male calling bout duration in a field cricket. Behav. Ecol. Sociobiol., 19, 73-77.

Huber, F. \& Thorson, J. 1985. Cricket auditory communication. Scient. Am., 253, 60-68.

K halifa, A. 1950. Sexual behavior in Gryllus domesticus L. Behaviour, 2, 264-274.

Kodric-Brown, A. \& Brown, J. H. 1984. Truth in advertising: the kinds of traits favored by sexual selection. Am. Nat., 124, 309-323.
Møller, A. P. 1994. Sexual Selection and the Barn Swallow. Oxford: Oxford U niversity Press.

M urtaugh, M . P. \& D enlinger, D . L . 1985. Physiological regulation of long-term oviposition in the house cricket, A cheta domesticus. J . Insect P hysiol., 31, 611617.

M urtaugh, M. P. \& D enlinger, D. L. 1987. R egulation of long-term oviposition in the house cricket, A cheta domesticus: roles of prostaglandin and factors associated with sperm. A rchs Insect Biochem. Physiol., 6, 59-72.

Prestwich, K. N. \& W Walker, T. J. 1981. Energetics of singing in crickets: effect of temperature in three trilling species (Orthoptera: Gryllidae). J. comp. Physiol., 143, 199-212.

Sakaluk, S. K. \& Cade, W. H. 1983. The adaptive significance of female multiple matings in house and field crickets. In: O rthopteran M ating Systems: Sexual Competition in a Diverse Group of Insects ( $E d$. by D. K. G wynne \& G. K. M orris), pp. 319-336. Boulder, Colorado: Westview Press.

Searcy, W. A. \& A ndersson, M. 1986. Sexual selection and the evolution of song. A. R ev. Ecol. Syst., 17, 507-533.

Simmons, L. W. 1987. Heritability of a male character chosen by females of the field cricket, Gryllus bimaculatus. B ehav. E col. Sociobiol., 21, 129-133.

Simmons, L. W. 1988. The calling song of the field cricket, Gryllus bimaculatus ( $D$ e $G$ eer): constraints on transmission and its role in intermale competition and female choice. A nim. B ehav., 36, 380-394.

Simmons, L. W. 1995. Correlates of male quality in the field cricket, Gryllus campestris L.: age, size, and symmetry determine pairing success in field populations. B ehav. E col., 6, 376-381.

Simmons, L. W. \& Ritchie, M. G. 1996. Symmetry in the songs of crickets. Proc. R. Soc. L ond. Ser. B, 263, 305-311.

Simons, A. M. \& Roff, D. A. 1994. The effect of environmental variability on the heritabilities of traits of a field cricket. E volution, 48, 1637-1649.

Simmons, L. W. \& Zuk, M. 1992. Variability in call structure and pairing success of male field crickets, Gryllus bimaculatus: the effects of age, size, and parasite load. A nim. B ehav., 44, 1145-1152.

Solymar, B. D. \& Cade, W. H. 1990. H eritable variation for female mating frequency in field crickets, Gryllus integer. B ehav. E col. Sociobiol., 26, 73-76.

Souroukis, K. \& Cade, W. H. 1993. Reproductive competition and selection on male traits at varying sex ratios in the field cricket, Gryllus pennsylvanicus. B ehaviour, 126, 45-62.

Souroukis, K ., Cade, W. H . \& R owell, G . 1992. Factors that possibly influence variation in the calling song of field crickets: temperature, time, and male size, age, and wing morphology. Can. J. Z ool., 70, 950-955.

Stevens, E. D . \& J osephson, R . K . 1977. M etabolic rate and body temperature in singing katydids. Physiol. Z ool., 50, 31-42.

Stout, J. F. \& M cG hee, R. 1988. A ttractiveness of the male A cheta domestica calling song to females II. The relative importance of syllable period, intensity, and chirp rate. J. comp. P hysiol., 164, 277-287. 
Stout, J. F., DeH aan, C. H.\& M cG hee, R. W. 1983. A ttractiveness of the male A cheta domesticus calling song to females I. D ependence on each of the calling song features. J . comp. P hysiol., 153, 509-521.

Tuckerman, J . F., G wynne, D . T . \& M orris, G . K . 1993. R eliable acoustic cues for female mate preference in a katydid (Scudderia curvicauda, Orthoptera: Tettigoniidae). Behav. E col., 4, 106-113.

Wagner, W. E., J r, M urray, A . M . \& Cade, W . H . 1995. Phenotypic variation in the mating preferences of female field crickets, Gryllus integer. A nim. B ehav., 49, 1269-1281.
Weissman, D. B., R entz, D. C. F., A lexander, R. D.\& L oher, W . 1980. Field crickets (Gryllus and A cheta) of California and Baja California, M exico (Orthoptera: Gryllidae: Gryllinae). Trans. A m. entomol. Soc., 106, 327-356.

Zuk, M . 1987. Variability in attractiveness of male field crickets (Orthoptera: Gryllidae) to females. Anim. B ehav., 35, 1240-1248.

Zuk, M. 1988. Parasite load, body size, and age of wild-caught male field crickets (Orthoptera: Gryllidae): effects on sexual selection. Evolution, 42, 969976. 